\title{
Determining work-relatedness of acute shoulder trauma. review 2017
}

\begin{abstract}
The chronicity of rotator cuff tears and their cause with increasing age has been extensively studied resulting in widely varying prevalence estimates. Focusing on a reported prevalence rate that increases with age to as high as $80 \%$ for 70 year olds can result in denial of reimbursement for work-related rotator cuff tears based on the presumed existence of underlying tendon pathology. The age at which inherent degeneration of the rotator cuff becomes a consideration in worker's comp judgments is vague at best. There are instances of acute shoulder trauma that occur in individuals as young as 20 years and even younger in athletes before significant tendon degeneration occurs. Multiple studies report low prevalence rates of asymptomatic rotator cuff tears in individuals less than 50 years. Acute shoulder trauma occurring at work in young workers provides strong evidence that the exposure event underlies any resulting shoulder disorder rather than tendon degeneration and as such is compensable. It can be questioned whether work-related acute shoulder trauma occurring at any age should be attributed to inherent tendon degeneration.
\end{abstract}

Volume 8 Issue 4 - 2017

\author{
Blair A Rhode, William S Rhode \\ Orland Park Orthopedics, USA
}

Correspondence: Blair A Rhode, Orland Park Orthopedics, I6450 S 104th AV, Orland Park, Illinois 60467, USA, Tel 708-364844I, Fax 708-364-8443, Email blairbones@gmail.com

Received: May 24, 2017 | Published: June 20, 2017

\section{Introduction}

Rotator cuff disease is the most common upper extremity disability. ${ }^{1}$ Tendons are connective tissues primarily made up of aligned type I collagen fibrils. The primary cells in tendons are fibroblasts which produce the extra cellular matrix components. As a tendon ages, there is a drop in both cell numbers and cell synthetic activity which could affect mechanical function as tendon structure and composition are altered. These changes likely underlie the increase in tendon injuries with aging. ${ }^{2}$ The principal focus of this review is the determination between acute traumatic and chronic degenerative rotator cuff tears (RCTs) which has huge implications for compensation of work-related injuries. Determining the underlying cause of an RCT is complicated by an increasing incidence of asymptomatic rotator cuff disease with increasing age due to ongoing degeneration of the shoulder tendons. As the age of patient's increases and along with possible RC degeneration, it becomes increasingly difficult to exclusively attribute shoulder injuries to work-related trauma. However, ethically and given the original intent of worker compensation legislation, workrelated trauma to the shoulder should be compensable. ${ }^{3}$

Determining the chronicity of tendon tears remains an issue that is still being pursued. Codman in 1931 stated four prescient hypotheses for RC supraspinatus tendon lesions: (1) trauma, (2) calcification, (3) necrosis or osteoarthritis, or (4) direct result of attrition. ${ }^{4}$ Extrinsic and intrinsic factors are recognized to affect rotator cuff tears. Neer identified extrinsic factors based on impingement of the cuff against the coracoacromial arch when the arm is elevated in a forward direction leading to tendonitis and tears. ${ }^{5}$ Variable morphology of the acromion includes spurs ${ }^{6-8}$ and a hook-shaped acromion ${ }^{9,}{ }^{10}$ that influence the degree of impingement and likelihood of a tear ${ }^{11}$ though acromial morphological variation and its relation to impingement needs to be further explored. ${ }^{12,13}$ The focus here in on the multifactorial theories of tendinopathy that include: tensile overload, load-inducing ischemia, and adaptive compressive responses.

Increasing tendon-tensile loads can cause plastic deformation that will eventually rupture a tendon. The most common rotator cuff tendon to rupture is the supraspinatus tendon (SST) and it is also affected by insertional tendinopathy. Tendon strength is dependent on loading history. When the tendon is subjected to increasing loads with higher frequency and/or longer duration the tendon may not adapt. Excessive tensile loads that exceed tendon mechanical strength are capable of causing plastic deformation which may lead to a tear. If the plastic deformation is small there may be a microinjury that increases with repeated episodes to produce a clinically significant injury. ${ }^{14}$ SST tearing is usually found on the humeral side of the joint. Acute injuries usually result from trauma while chronic injuries are often due to repetitive mechanical events that result in inflammation.

Tendons have unique viscoelastic properties that result in a unique mechanical behavior. A tendon stress-strain curve illustrates key regions of operation. With no force applied to the tendon the fibers are crimped. When an SST is ruptured, there is a crimped appearance in the tendon in the initial period that is indicative that it is a recent rupture and may be critical in determining an acute versus degenerative tear. ${ }^{15-18}$ As larger strains are applied the tendon operates in a linear region until with yet larger strains there are microscopic breaks in the fibers that increase until at an ultimate failure load (UFL) the tendon ruptures.

The fate of a tendon exposed to a range of loads that are cycled repeatedly varies with the maximum load and rate of cycling. When tendon stretch exceeds its elastic range, it does not return to its original length at the end of each cycle due to plastic deformation. However, if the microfiber damage does not reach failure level the tendon will recover with time. This is made possible by the presence of tendon stem cells that differentiate into tenocytes and play an important role in tendon maintenance and repair. ${ }^{17}$ A porcine SST exposed to a load that exceeds its plastic range results in a breakdown of the fibers that would ultimately lead to a complete tear shown in (Figure 1).

In a set of German studies designed to establish criteria for acute shoulder trauma versus chronic degeneration forty years has been employed as an age when 'normal' rotator cuff degeneration becomes a consideration in determining an individuals' shoulder status. ${ }^{17,19-23}$ Clinical observation of hematoma, swelling, drop-arm, and characteristic power loss with no secondary changes to the humeral head and acromion seen in a radiograph indicates an acute event. Supporting evidence for an RCT due to trauma includes ultrasonography within 2 weeks of the event that shows rupture and haematologic bursa and an MRI conducted within 6 weeks of the acute 
event showing a rupture and bone edema. Histology within 12 weeks of the event finding fibroblasts and granulation indicates trauma. Follow up radiographs should demonstrate progression of secondary changes, while ultrasound imaging of the opposite shoulder indicates no damage and/or a radiograph of the opposite side is negative for shoulder degeneration. ${ }^{17}$ The initial step in judging a rotator cuff tendon tear to be work-related is documentation of any acute trauma event that resulted in reduced shoulder function. Clinical examination along with documentation of the RCT by imaging is necessary. Patient age at the time of the event and current health condition are factors that influence attribution of an RCT to either a work-related event or normal degeneration of the $\mathrm{RC}$.

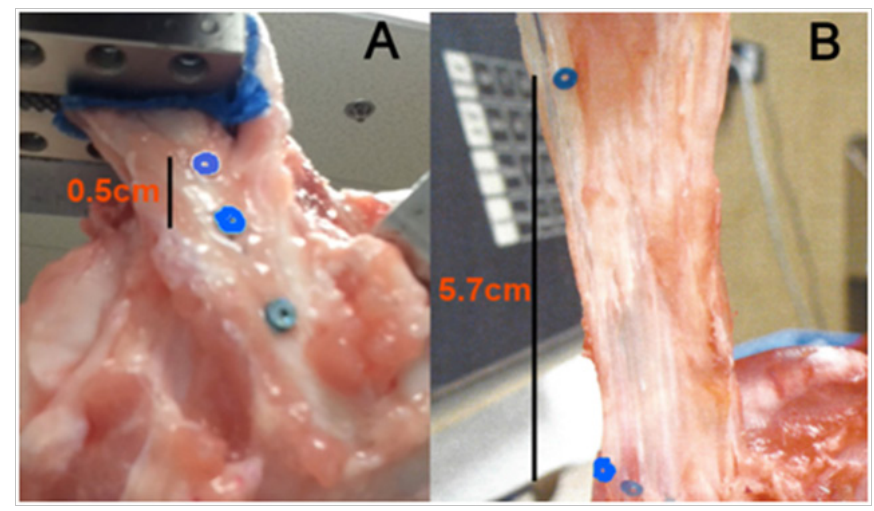

Figure I A.A porcine SST tendon in a measurement/test instrument before a load is applied. Three $\mathrm{mm}$ in diameter reflective discs serve to monitor tendon stretch. B. Tendon stretch after the plastic range of the tendon has been exceeded illustrates tendon thinning.

\section{Determining That an RCT is Based on Trauma}

In the Summary of a workshop on Work-Related Musculoskeletal Disorders, the National Research Council summarized "conditions" or "conventions" for causation. Five characteristics were settled on as necessary to support a work-related condition: (1) temporal ordering requires the cause to be present before the condition, (2) that exposure and outcome covary, for example a force produces a response in a tendon, (3) the absence of other plausible explanations implies that confounding factors are controlled for by the experimental design, (4) temporal contiguity implies cause and effect are simultaneous, and (5) congruity between exposure and outcome implies a proportional response between cause and effect. These characteristics serve as criteria when reviewing individual studies for their likelihood of generating causal inferences. ${ }^{25}$

\section{Distinguishing between acute trauma and degenerative RCTS}

An early effort in 1994 was made to address the issue of rotator cuff trauma being the result of degeneration or due to an accident. ${ }^{17}$ The difficulty of demonstrating causality of a RC rupture led to an attempt to design a 20-point scoring system that could be used for legal and insurance purposes. Correlation between trauma and an RCT was to be based on four factors: history, trauma mechanism, initial finding and the course of the functional deficit. The 20-pt score consisted of history (2 pts), trauma mechanism ( 3 pts), initial clinical and imaging (10 pts) and course of the deficit (5 pts). The score was intended to be used to classify the trauma as either the main or partial cause or as irrelevant to the RCT pathogenesis. In 2000 the effort to provide a recommendation for the diagnosis and legal assessment of traumatic RCTs, Loew et al presented the pro- and contra- arguments in two tables..$^{20,22,23}$
MRI and radiological conditions necessary to distinguish trauma induced rotator cuff tears from age-related degenerative rotator cuff tears was recently made. ${ }^{17}$ The study divided 50 patients with RCTs confirmed by MRI into those with a history of trauma within the previous 6 weeks and no pre-existing shoulder pain and those with shoulder pain for less than 12 months and no trauma history.

\section{Rotator cuff tears resulting from degeneration}

Rotator cuff lesions resulting from age-related degenerative changes are more likely when there is no history of injury, no doctor visit within two weeks of initial pain, clinical signs of muscular atrophy of SST/IST/deltoid, cuff tear arthropathy, imaging of opposite side indicating rupture, no blood in joint and smooth tendon margins. ${ }^{20}$ Similarly, Sallay concluded that chronic RCTs had an insidious onset of symptoms or a history longer than 6 weeks with signs of healing and remodeling at the tear edge. ${ }^{26}$

Rotator cuff tears increase with age though many individuals remain asymptomatic. Prevalence of rotator cuff abnormalities increases with age making assigning cause to new symptoms problematic. ${ }^{27}$ Interpreting diagnostic test results given age related degeneration is also problematic in determining whether an abnormality is new or even the direct cause of patient symptoms. This poses a difficulty in securing patient rights when RCTs are likely due to work-related trauma rather than age-related degenerative changes. ${ }^{28}$ Meyer pointed out in 1924 that when it is remembered that many an industrial worker repeats approximately the same movement tens of thousands of times a day, not merely for days, but for weeks, months, years, and even for decades, the entire lack of evidence of unrepaired effects of internal attrition from occupational or other movements seems all the more surprising. It seems needless to add that occupation and to a certain extent the habits of an individual undoubtedly are very important factors in the matter under consideration. ${ }^{29}$ Age is a factor of great importance in RCT causality. Correlation has been demonstrated between age and maximum strength, age and tendon stiffness, and stiffness and maximum strength. However, caution in applying correlations to individual cases is warranted as researchers noted the occurrence of $900 \mathrm{~N}(\sim 200 \mathrm{lbs})$ maximum tensile strength in a 65 -year old tendon specimen suggesting even at 65 the tendon can be plenty strong. ${ }^{30}$

\section{Asymptomatic FTRCTs increase with age}

While asymptomatic full thickness rotator cuff tears increase with age and tear rate for age $>70$ years has been reported to be over $50 \%$, there are few examples of FTRCTs for patients younger than 40 years. Multiple studies of RCTs addressed the occurrence as a function of patient age. ${ }^{28,31-42}$ While patient age is almost always recorded, many studies either were not large enough to correlate prevalence with age or failed to do so in their reports. Thirteen reports that provided age data are listed in Table 1 along with the prevalence rate for FTRCTs in age deciles. In a few instances prevalence rates were assigned to multiple decile ranges indicated by square brackets in (Table 1). . $^{30,32,38}$ For age $<50$ the prevalence rate is close to 0 in all studies. In the 50 59 age range the average prevalence rate for the 10 studies reporting is $5.5 \%$. For the $60-69$ age range, the prevalence rate in the seven studies that reported data in this range, the prevalence rate is $14.6 \%$. The prevalence rates for the first decile of a multi-decile reports would likely be substantially less than the $13.5 \%, 27 \%$ and $33 \%$ shown in the table based on the demonstrated systematic increase with age. When all studies except for the two smallest are factored in, the prevalence rate for the $60-69$ group is $16.2 \%$ with range of $5.7-27 \%$. These low prevalence rates for FTRCTs for age $<50$ strongly support assigning a causal relation to a reported acute trauma to the shoulder. In fact, 
this assignment of cause appears to be valid for the 50-59 age range and likely in most instances of acute trauma in the 60-69 age range. Further support for acute trauma as the cause for FTRCTs rather than age related degeneration of the rotator cuff is provided by several cadaver studies (Tables 2A \& 2B). The prevalence of FTRCTs for age $<50$ is near 0 and very low for the 51-60 age range. For age $>$
70 the prevalence rate increases to values as high as $60 \%$ Tables 1 \& 2 indicate a low prevalence rate for FTRCTs in asymptomatic individuals and in cadavers younger than 60 years. Based on these data it appears that FTRCTs found clinically for patients observed within a few days of an acute traumatic event with shoulder pain result from the trauma rather than normal degeneration of the RC.

Table I Per cent Asymptomatic full thickness rotator cuff tears by age group

\begin{tabular}{|c|c|c|c|c|c|c|c|c|}
\hline & & $<40 \mathrm{yr}$ & $40-49$ & $50-59$ & $60-69$ & $70-79$ & $>79$ & $\mathbf{N}$ \\
\hline Sher & $1995^{31}$ & 0 & [---------- & I--------] & [--------- & |3.5------ & ] & 100 \\
\hline Needell & $1996^{32}$ & 0 & [----- & 4--------] & [----- & -----27----- & ---------] & 100 \\
\hline Milgrom & $1999^{33}$ & 0 & 0 & 18 & 29 & 39 & 44 & 90 \\
\hline Templehof & 199928 & & & 13 & 20 & 31 & 51 & $4 I I$ \\
\hline Schibany & $2004^{34}$ & & 0 & 1 & 14 & 7 & & 212 \\
\hline Moosmayer & $2009^{35}$ & & & 2.1 & 5.7 & 15 & & 420 \\
\hline Kim & $2009^{36}$ & & 0 & 7.1 & 8.3 & 29.6 & & 237 \\
\hline Yamamoto & $2010^{37}$ & 2.5 & 6.7 & 12.8 & 25.6 & 45.8 & 50 & 683 \\
\hline Yu & $2012^{38}$ & 0 & 0 & 0 & [------ & ----33----- & ---------] & 45 \\
\hline Minagawa & $2013^{39}$ & 0 & 0 & 10.7 & 15.2 & 26.5 & 36.6 & 664 \\
\hline Jeong & $2017^{40}$ & & 0 & 3.5 & 13.3 & II.I & & 486 \\
\hline dePalma & $1950^{41}$ & 0 & & & & & & \\
\hline Hawkins & $1999^{42}$ & 2 & & & & & & 19 \\
\hline
\end{tabular}

Table 2A Prevalence of FTRCTs in cadaver shoulders

\begin{tabular}{|c|c|c|c|c|c|c|c|c|c|}
\hline Age & & $38-40$ & $41-50$ & $51-60$ & $61-70$ & $71-80$ & $81-90$ & $91-95$ & $\mathbf{N}$ \\
\hline Keyes & $1933^{43}$ & 0 & 0 & [-------- & -------3|- & ---------- & ----------] & & 73 \\
\hline Petersson & $1983^{44}$ & 0 & 0 & 0 & II & 21 & 17 & 60 & $|5|$ \\
\hline Ozaki & $1988^{45}$ & 0 & 0 & 0 & 4.8 & 15.6 & 20.5 & 37.5 & 200 \\
\hline Hijoki & $1993^{46}$ & & 0 & 0 & 13 & 15.2 & 10 & 50 & 80 \\
\hline Lehman & $1995^{47}$ & & & $6<60$ & $30>60$ & & & & 456 \\
\hline
\end{tabular}

Table 2B Prevalence of FTRCTs in cadaver shoulders (age ranges different than in Table 2A)

\begin{tabular}{|c|c|c|c|c|c|c|c|}
\hline Age & & $17-46$ & $47-56$ & $57-66$ & $67-76$ & $77-86$ & $\mathbf{N}$ \\
\hline Grant & $1988^{48}$ & 0 & 25 & 18 & 39 & 50 & 95 \\
\hline Panni & $1996^{49}$ & 0 & [---------0 & ------------] & [-----26.7 & -------------] & 80 \\
\hline
\end{tabular}

Table 3 Prevalence of asymptomatic RCTs from a review of 30 studies (Table $\mathrm{II}^{27}$ )

\begin{tabular}{|c|c|c|c|c|c|c|c|c|c|c|}
\hline Age & & $<20$ & $20-29$ & $30-39$ & $40-49$ & $50-59$ & $60-69$ & $70-79$ & $>80$ & $\mathbf{N}$ \\
\hline Tuenis & $2014^{27}$ & 0 & 6.7 & 21 & 4 & 9.5 & 16 & 28 & 56 & 6112 \\
\hline
\end{tabular}

\section{Acute shoulder trauma or rotator cuff degeneration?}

A review of rotator cuff tear studies in 2014 that included asymptomatic patients, the general population, symptomatic patients, and patients with a shoulder dislocation by the Harvard group concluded that nearly all rotator cuff pathology can be attributed to a degenerative process and challenged the existence of trauma as a causative factor. ${ }^{25}$ Normal degeneration of the RC makes it difficult to decide whether any abnormality is new or even the cause of the symptoms. The high prevalence of asymptomatic abnormalities makes interpretation of diagnostic tests and radiologic findings difficult and therefore the clinical assignment of direct cause as either due to an acute trauma event or simply RC attrition can be challenging. However, the conclusions of the Review are only weakly related to individuals with FTRCTs that result from a recent acute shoulder trauma, the focus of this article. ${ }^{27}$ Table 3 lists the prevalence findings of the Review limited to asymptomatic RCTs. ${ }^{27}$ The prevalence rates for the 3rd through 5th deciles are 6.7,21 and 4\% respectively. The $21 \%$ prevalence for the $30-39$-year range deviates from an expected systematic increase in prevalence with age which is clear for age $>50$ in nearly every study of prevalence in the literature and in their Table II for the overall, general, symptomatic populations. This is an odd result given the high shoulder count $(\mathrm{N}=6112)$ used in the review. This result suggests a sampling problem in the chosen studies for Table 3 of the Review. ${ }^{27} \mathrm{~A}$ further complication for comparison purposes with the FTRCT results shown in Table 1 and 2 here is that both partial and full tears of the supraspinatus are included the review. All the studies of asymptomatic individuals with RCTs included in their review are included in Table 1 here except for those studies that were specialized: Lesniak (asymptomatic pitchers), Abate (postmenopausal women), and Iagnocco (both PT and FTs) though it is noteworthy that the latter study reported a very low prevalence rate $<2.6 \%$ in the $40-59$ age range.

\section{An argument for early repair based on human and animal studies}

Both human and animal RCT studies have focused on the effect of delay of repair. Outcomes have supported early repair though some studies reported that delay of up to one year has no effect on clinical outcome. A rat SST model considered similar to human $\mathrm{RC}$, demonstrated an increase in cellularity and loss of collagen due to overuse. ${ }^{50}$ With use, mechanical properties deteriorated with a decreased modulus of elasticity, a change that could predispose a tendon to degeneration and rupture. In another study, sixty rat supraspinatus tendons were transected and divided in two groups, immediate repair and delayed repair after three weeks. RC healing was inferior in the delayed group with markedly decreased bone density that may result in poor healing. ${ }^{51}$ 
The infraspinatus tendon was released in 36 sheep that were divided into 3 equal groups that were repaired either immediately, after six weeks and after 18 weeks. Early repair of the tendon resulted in a more rapid recovery of both muscle function and tendon elasticity. It was suggested that there may be a 'point of no return' in rotator cuff injury after which the muscle-tendon unit does not return to normal. ${ }^{52}$ Three groups of patients with acute traumatic shoulder injuries underwent RC repair within 3 weeks, between 3 and 6 weeks, and between 6 and 12 weeks respectively. The early repair group had the best functional results. ${ }^{53}$ For patients that had sudden onset of symptoms and significant impairment of function due to a full RC tear, the results of early operative treatment were better than conservative treatment or late surgery. A similar result was obtained for a group of patients operated on within 3 weeks of the beginning of their symptoms..$^{54}$ In fact, early operative treatment was beneficial regardless of tear type if the onset of symptoms was acute. It was suggested that with an increasing delay to repair, the tear may enlarge, and the cuff may lose its elasticity, thus making the late surgical repair more difficult or even impossible.

In a retrospective case control study, the mean elapsed time from injury to RC repair was 11 weeks with a range of 2 to 25 weeks. Rotator cuff tear size had no effect on patient outcome except massive tears repaired after 4 months had the worst outcomes. In general, repairs were not compromised up to 4 months after injury. ${ }^{55}$ Arthroscopic repair of FTRCTs (95\% were traumatic tears) returned to preinjury level of function in $95 \%$ of patients in a group of patients younger than 40 years. ${ }^{56}$ The result of a retrospective analysis of prospectively collected data on patients presenting with acute rotator cuff tears was that early repair resulted in improved outcomes. ${ }^{57} \mathrm{In}$ a case-controlled study of expedited RC surgery in injured workers, the early repaired group of 119 patients was more likely to be working at the final follow up than the control group of 65 patients. ${ }^{58}$

A group of 23 patients younger than 40 years who were treated with arthroscopic rotator cuff repair for full-thickness RCTs were examined. The etiology appeared to be traumatic in nature in $95 \%$ of the patients. Successful RC repair returned $95 \%$ of the patients to preinjury level of function. It was concluded that the results support early arthroscopic rotator cuff repair in young, active patients. ${ }^{54}$ While age is considered a major factor in determining traumatic vs overuse, after review of 12 nonprospective case series, Lazarides concluded that RCTs in young patients is a different disease than found in the elderly. ${ }^{59}$ Their most common injury was a full thickness tear of the SST. While there appears to be some disagreement over the optimum time to repair RC after acute trauma, outcomes appear to be better when repair is performed as soon after the tear as possible. Both animal and human studies support this conclusion.

\section{Conclusion}

In full thickness rotator cuff tears that result from acute trauma either from an accident or work related event; degeneration of the shoulder is not a factor for patient age less than 59 years. The argument can be made that for work-related trauma that degeneration with age is at best a minor factor. The healthy survivor effect contributes to eliminating from the work pool individuals who feel excessively challenged by the job physical requirements. The healthy survivor effect should contribute to all work-related acute shoulder trauma passing legal and insurance muster for compensation regardless of age. A related issue is disabling shoulder trauma resulting from work exposure due to repetition, hands above the head with heavy loads, and a variety of conditions has been documented by several scientific bodies. Trauma and work exposure have to be properly documented during the clinical exam. An MRI is necessary for discriminating between traumatic and non-traumatic RCTs when the shoulder is imaged within a few days of the event. However, an MRI cannot determine chronicity if the shoulder is not imaged early after an acute event as edema and muscular atrophy will frequently be present. ${ }^{60-63}$

Determining a causal relation between an accident or workrelated acute event and a resulting $\mathrm{RC}$ tear is clear cut when patients are clinically evaluated within a few days of the event and shoulder imaging is performed. Given the relatively low prevalence rate of asymptomatic FTRCTs for age $<50$, rotator cuff tendon degeneration is not likely a contributing factor. Though the prevalence rate for FTRCTs increases with age $>50$, between 50 to 59 it remains only $5.5 \%$, low enough that when worker healthy survivor effects are factored into the clinical decision, the occurrence of an acute trauma event should be sufficient for establishing cause. Based on both human and animal studies, it appears that RCTs should be repaired as early as possible for the best patient outcomes.

\section{Conflicts of interest}

None.

\section{Acknowledgments}

None.

\section{References}

1. Gomoll AH, Katz JN, Warner JJP, et al. Rotator Cuff Disorders Recognition and management among patients with shoulder pain. Arthritis Rheum. 2004;50(12):3751-3761.

2. Albers IS, Zwerver J, Diercks RL, et al. Incidence and prevalence of lower extremity tendinopathy in a Dutch general practice population: a cross sectional study. BMC Muscloskelet Disorde. 2016;17:1-6.

3. Dembe AE. Access to medical care for occupational disorders: Difficulties and disparities. J Health Soc Policy. 2001;12(4):19-33.

4. Codman EA, Akerson IB. The pathology associated with the of the supraspinatus tendon. Ann Surg. 1931;93(1):348-359.

5. Neer CS 2 $2^{\text {nd }}$. Impingement lesions. Clin Orthop Relat Res $1983 ; 173: 70-77$.

6. Hamid N, Omid R, Yamaguchi K, et al. Relationship of radiographic acromial characteristics and rotator cuff disease: a prospective investigation of clinical, radiographic, and sonographic findings. $J$ Shoulder Elbow Surg. 2012;21(10):1289-1298.

7. Ogawa K, Yoshida A, Inokuchi W, et al. Acromial spur: relationship to aging and morphologic changes in the rotator cuff. J Shoulder Elbow Surg. 2005;14(6):591-598.

8. Ozaki J, Fujimoto S, Nakagawa Y, et al. Tears of the rotator cuff of the shoulder associated with pathological changes in the acromion. $J$ Bone Joint Surg Am. 1988;70(8):1224-1230.

9. Epstein RE, Schweitzer ME, Frieman BG, et al. Hooked acromion: prevalence on MR images of painful shoulders. Radiology. 1993;187(2):479-481.

10. Nicholson GP, Goodman DA, Flatow EL, et al. The acromion: morphologic condition and age-related changes. A study of 420 scapulas. J Shoulder Elbow Surg. 1996;5(1):1-11.

11. Bigliani LU, D Alessandro DF, Duralde XA, et al. Anterior acromioplasty for subacromial impingement in patients younger than 40 years of age. Clin Orthop Relat Res. 1989;246:111-116.

12. Li X, Xu W, Hu N, et al. Relationship between acromial morphological variation and subacromial impingement: A three-dimensional analysis. 2017;12(4):e0176193. 
13. Mackenzie TA, Herrington L, Horlsey I, et al. An evidence-based review of current perceptions with regard to the subacromial space in shoulder impingement syndromes: Is it important and what influences it? Clin Biomech. 2015;30(7):641-648.

14. Almekinders LC, Weinfold PS, Maffuli N. Compression etiology in tendinopathy. Clin Sports Med. 2003;22(4):703-710.

15. Wilmink J, Wilson AM, Goodship AE. Functional significance of the morphology of and micromechanics of collagen fibres in relation to the partial rupture of the superficial digital flexor tendon in racehorses. Res Vet Sci. 1992;53(2):354-359.

16. Neviaser A, Andarawis-Puri N, Flatow E. Basic mechanisms of tendon fatigue damage. J Shoulder Elbow Surg. 2012;21(2):158-163.

17. Wang JH, Guo Q, Li B. Tendon Biomechanics and Mechanobiology-A Minireview of Basic Concepts and Recent Advancements. J Hand Ther. 2012;25(2):133-139.

18. Loew M, Magosch P, Lichtenberg S, et al. How to discriminate between acute traumatic and chronic degenerative rotator cuff lesions: an analysis of specific criteria on radiography and magnetic resonance imaging. $J$ Shoul Elbow Surg. 2015;24(11):1685-1693.

19. Loew M, Rompe G. Criteria for legal assessment of rotator cuff rupture. Unfallchirurg. 1994;97(3):121-126.

20. Loew M, Habermeyer P, Wiedemann E, et al. Recommendations for diagnosis and legal assessment of traumatic rotator cuff tears. Unfallchirurg. 2000;103(5):417-426.

21. Braune C, Gramlich H, Habermeyer P. The macroscopic aspect of rotator cuff tears in traumatic and nontraumatic rupture cases. Unfallchirurg. 2000;103(6):462-467.

22. Loew M. Trauma-related rotator cuff injury: Scientific basis and consequences for legal assessment. Der Orthopäde. 2000;29(10):881-887.

23. Lehner B, Loew M. Etiology of Rotator-Cuff-Tears and Consequences for Legal Assessment. Zentralbl Chir. 2002;127(3):187-193.

24. Braune C, von Eisenhart-Rothe R, Welsch F, et al. Mid-term results and quantitative comparison of postoperative shoulder function in traumatic and non-traumatic rotator cuff tears. Arch Orthop Trauma Surg. 2003;123(8):419-424

25. National Research Council. Work-Related Musculoskeletal Disorders Report, Workshop Summary, and Workshop Papers. Steering Committee for the Workshop on Work-Related Musculoskeletal Injuries: The Research Base. 1999.

26. Sallay PI, Hunker PJ, Lim JK. Frequency of various tear patterns in fullthickness tears of the rotator cuff. Arthroscopy. 2007;23(10):1052-1059.

27. Teunis T, Lubberts B, Reilly BT, et al. A systematic review and pooled analysis of the prevalence of rotator cuff disease with increasing age. $J$ Shoulder Elbow Surg. 2014;23(12):1913-1921.

28. Tempelhof S, Rupp S, Seil R. Age-related prevalence of rotator cuff tears in asymptomatic shoulders. J Shoulder Elbow Surg. 1999;8(4):296-299.

29. Meyer L. orthopaedic surgeon and industrial accidents. Internat J Surg 1924;37:231-235.

30. Rickert M, Georgousis H, Witzel U. The native tensile strength of the supraspinatus tendon. A biomechanical study. Unfallchirurg. 1998;101(4):265-270.

31. Sher JS, Uribe JW, Posada A, et al. Abnormal Findings on Magnetic Resonance Images of Asymptomatic Shoulders. J Bone Joint Surg. 1995;77(1):10-15.

32. Needell SD, Zlatkin MB, Sher JS, et al. MR Imaging of the rotator cuff: Peritendinous and bone abnormalities in an asymptomatic population. Am J Roent. 1996;166(4):863-867.
33. Milgrom C, Schaffler M, Gilbert S, et al. Rotator-cuff changes in asymptomatic adults. The effect of age, hand dominance and gender. $J$ Bone Joint Surg Br. 1995;77(2):296-298.

34. Schibany N, Zehetgruber H, Kainberger F, et al. Rotator cuff tears in asymptomatic individuals: a clinical and ultrasonographic screening study. Eur J Radiol. 2004;51(3):263-268.

35. Moosmayer S, Smith HJ, Tariq R, et al. Prevalence and characteristics of asymptomatic tears of the rotator cuff: an ultrasonographic and clinical study. J Bone Joint Surg Br. 2009;91(2):196-200.

36. Kim HM, Teefey SA, Zelig A, et al. Shoulder strength in asymptomatic individuals with intact compared with torn rotator cuffs. $J$ Bone Joint Surg Am. 2009;91(2):289-296.

37. Yamamoto A, Takagishi K, Osawa T, et al. Prevalence and risk factors of a rotator cuff tear in the general population. J Shoulder Elbow Surg. 2010;19(1):116-120

38. Yu TY, Tsai WC, Cheng JW, et al. The Effects of Aging on Quantitative Sonographic Features of Rotator Cuff Tendons. J Clin Ultrasound. 2012;40(8):471-478.

39. Minagawa $\mathrm{H}$, Yamamoto $\mathrm{N}$, Abe $\mathrm{H}$, et al. Prevalence of symptomatic and asymptomatic rotator cuff tears in the general population: From mass-screening in one village. J Orthopaedics. 2013;10(1):8-12.

40. Jeong J, Shin DC, Kim TH, et al. Prevalence of asymptomatic rotator cuff tear and their related factors in the Korean population. J Shoulder Elbow Surg. 2017;26(1):30-35.

41. DePalma AF. Degenerative lesions of the shoulder joint at various age groups which are compatible with good function. In Instructional Course Lectures, The Am Acad Orthopaedic Surg. 1952;7:168-180.

42. Hawkins RJ, Morin WD, Bonutti PM. Surgical treatment of fullthickness rotator cuff tears in patients 40 years of age or younger. $J$ Shoulder Elbow Surg. 1999;8(3):259-265.

43. Keyes EL. Observations on rupture of the supraspinatus tendon: Based upon a study of seventy-three cadavers. Ann Surg. 1933;97(6):849-856.

44. Petersson CJ, Gentz CF. Ruptures of the supraspinatus tendon. The significance of distally pointing acromioclavicular osteophytes. Clin Orthop Relat Res. 1983;(174):143-148.

45. Ozaki J, Fujimoto S, Nakagawa Y, et al. Tear of the rotator cuff of the shoulder associated with pathological changes of the acromium. $J$ Bone Joint Surg Am. 1988;70(8):1214-1230.

46. Hijoki A, Suzuki K, Nakamura, et al. Degenerative change and rotator cuff tears. An anatomical study in 160 shoulders of 80 cadavers. Arch Orthop Trauma Surg. 1993;112(2):61-64.

47. Lehman C, Cuomo F, Kummer FJ, et al. The prevalence of full thickness rotator cuff tears in a large cadaveric population. Bull Hosp Joint Dis. 1995;54(1):30-31.

48. Grant JCB, Smith CG. Age incidence of rupture of the supraspinatus tendon. Anat Rec. 1948;100:666-669.

49. Panni AS, Milano G, Lucania L, et al. Histological analysis of the coracoacromial arch: Correlation between age related changes and rotator cuff tears. Arthroscopy. 1996;12(5):531-540.

50. Soslowsky LJ, Thomopoulos S, Flanagan CL, et al. Neer Award 1999. Overuse activity injures the supraspinatus tendon in an animal model: a histologic and biomechanical study. J Shoul Elbow Surg. 2000;9(2):79-84.

51. Galatz LM, Ball CM, Teefey SA, et al. The Outcome and Repair Integrity of Completely Arthroscopically Repaired Large and Massive Rotator Cuff Tears. J Bone Joint Surg Am. 2004;86-A(2):219-224.

52. Coleman SH, Fealy S, Ehteshami JR, et al. Chronic rotator cuff injury and repair model in sheep. J Bone Joint Surg Am. 2003;85(12):2391-2402. 
53. Bassett RW, Cofield RH. Acute tears of the rotator cuff: the timing of surgical repair. Clin Orthop Relat Res. 1983;(175):18-24.

54. Lähteenmäki HE, Virolainen P, Hiltunen A, et al. Results of early operative treatment of rotator cuff tears with acute symptoms. J Shoulder Elbow Surg. 2006;15(2):148-153.

55. Petersen SA, Murphy TP. The timing of rotator cuff repair for the restoration of Function. J Shoulder Elbow Surg. 2011;20(1):62-68.

56. Krishnan SG, Harkins DC, Schiffern SC, et al. Arthroscopic repair of full-thickness tears of the rotator cuff in patients younger than 40 years. Arthroscopy. 2008;24(3):324-328.

57. Duncan NS, Booker SJ, Gooding BWT, et al. Surgery within 6 months of an acute rotator cuff tear significantly improves outcome. J Shoulder Elbow Surg. 2015;24(12):1876-1880.

58. Razmjou H, Lincoln S, Boljanovic D, et al. The effect of expedited rotator cuff surgery in injured workers: a case-control study. J Shoulder Elbow Surg. 2016;26(7):1196-1202.
59. Lazarides AL, Alentorn-Geli E, Choi JHJ, et al. Rotator cuff tears in young patients: a different disease than rotator cuff tears in elderly patients. J Shoulder Elbow Surg. 2015;24(11):1834-1844

60. Stadler A, Schima W, Ba-Ssalamah A, et al. Artifacts in body MR imaging: their appearance and how to eliminate them. Eur Radiol. 2007;17(5):1242-1255.

61. Motamedi D, Everist BM, Mahanty SR, et al. Pitfalls in Shoulder MRI: Part 1-Normal Anatomy and Anatomic Variants. Am J Roent. 2014;203(3):501-507.

62. Gyftopoulos S, Chitkara M, Bencardino JT. Misses and errors in upper extremity trauma radiographs. Am J Roent. 2014;203(3):477-491.

63. Roth E, Hoff M, Richardson ML, et al. Artifacts affecting musculoskeletal magnetic resonance imaging: Their origins and solutions. Current Problems Diagnostic Rad. 2016;45(5):340-346. 